\title{
Linguistic Mimicry and Trust in Text-Based CMC
}

\author{
Lauren E. Scissors, Alastair J. Gill, Darren Gergle \\ Center for Technology and Social Behavior \\ Northwestern University \\ 2240 Campus Drive, Evanston, IL 60208 USA \\ \{1-scissors, alastair, dgergle\}@northwestern.edu
}

\begin{abstract}
This study examines the relationship between linguistic mimicry and trust establishment in a text-chat environment. Twenty-six participant pairs engaged in a social dilemma investment game and chatted via Instant Messenger (IM) after every five rounds of investment. Results revealed that, within chat sessions, lexical mimicry (repetition of words or word phrases by both partners) was significantly higher for high-trusting pairs than for low-trusting pairs, but that lexical mimicry across chat sessions was significantly higher for low-trusting pairs than for high-trusting pairs. Theoretical and applied implications are discussed.
\end{abstract}

\section{Author Keywords}

Lexical Mimicry, Rapport, Trusting Language, Trust, Social Dilemma, Instant Messaging (IM)

\section{ACM Classification Keywords}

H.5.3 [Information Interfaces and Presentation]: Group and Organization Interfaces - collaborative computing, computer-supported cooperative work

\section{INTRODUCTION}

Behavioral mimicry is a well-established social phenomenon that has been shown to yield a number of collaborative benefits. People mimic one another's facial expressions [4], gestures and body posture [3, 8], and speech characteristics such as pitch, volume and rate [5]. This nonverbal and paralinguistic mimicry is hypothesized to serve as a form of social grooming that ultimately supports the fluidity of an interaction $[1,3]$. In other words, when speakers adapt their nonverbal behaviors to match those of their speaking partner, they indicate that they are accommodating and of like mind. These adaptations are associated with a number of outcomes including how much people like one another [3], perceived levels of credibility and attractiveness [10], and feelings of rapport [16].

What happens, however, when we interact in ComputerMediated Communication (CMC) environments that do not

Permission to make digital or hard copies of all or part of this work for personal or classroom use is granted without fee provided that copies are not made or distributed for profit or commercial advantage and that copies bear this notice and the full citation on the first page. To copy otherwise, or republish, to post on servers or to redistribute to lists, requires prior specific permission and/or a fee.

CSCW'08, November 8-12, 2008, San Diego, California, USA.

Copyright 2008 ACM 978-1-60558-007-4/08/11...\$5.00. provide support for the transmission of nonverbal or paralinguistic cues? Instant Messaging (IM), text (SMS) messages, and blog posts all occur in text-based environments where a number of these cues are not available. In such cases, do we fail to reap the social benefits of mimicry? Or, do we compensate by using a form of linguistic mimicry that makes use of the limited cues available? To explore this question, we examine the language of participant pairs who used IM to communicate during a trust-building task. We analyze the various forms of linguistic mimicry that take place during their IM discussions, and demonstrate a relationship between linguistic mimicry and overall trust outcomes.

At a theoretical level, the results of this work can be used to better understand the communication strategies individuals use in establishing trusting, successful relationships through text-chat. At an applied level, this work can inform the design and development of technologies to support geographically distributed work teams, online relationship building, or even online technical support communication.

\section{BACKGROUND LITERATURE}

Mimicry

Previous research has demonstrated that nonverbal mimicry in conversation can strengthen a relationship between individuals by increasing the degree to which they like one another [3] and build rapport [16]. While much of this research has examined the role of nonverbal mimicry such as body language and eye gaze, mimicry also exists at the verbal level. According to Communication Accommodation Theory, individuals may adjust their communication styles to be more or less like their communication partners [5], and converge on linguistic dimensions such as vocabulary or jargon as a way of signaling affinity toward their communication partners [17]. It is this convergence on linguistic dimensions that we term linguistic mimicry.

\section{Trust in CMC}

Early research questioned the efficacy of text-based CMC environments as vehicles through which trust could be established, suggesting that they did not provide enough nonverbal social cues to foster trust development [2]. More recent studies have challenged this view and demonstrated that that while trust may develop more swiftly in face-toface settings, individuals can reach similar levels of trust in text-based $\mathrm{CMC}$ environments when given enough time 
[18]. However, the vast majority of research on trust development in $\mathrm{CMC}$ focuses primarily on outcome measures of trust. Only recently has work begun to examine the processes by which groups develop trust. One mechanism through which we believe trust may be achieved is through the use of linguistic mimicry.

\section{Mimicry, Trust, and CMC}

Few studies have explicitly looked at the relationship between mimicry and trust. Recently, Maddux and colleagues examined the effect of nonverbal mimicry on negotiation outcomes and reported a mediating effect of trust, such that increased amounts of nonverbal mimicry of person $A$ increased the level of trust felt by person $B$ for $A$ [9]. However, this study only examined nonverbal mimicry that was induced by a confederate. Perhaps closest to this work is a study that examined linguistic style matching in text-based CMC environments [13], where pairs converged on the number of words used and across some content categories. However, the authors found little evidence of an association with rapport. While previous research has demonstrated the effects of nonverbal mimicry on outcomes such as rapport and liking, no studies to our knowledge have focused on the effects of linguistic mimicry on outcome measures of trust in computer-mediated environments. Drawing on both the linguistic mimicry and $\mathrm{CMC}$ trust literature, we hypothesize that in a text-chat environment, forms of linguistic mimicry will be correlated with higher levels of trust established between individuals.

\section{METHOD}

\section{Participants}

Participants ( $N=52,44 \%$ male, $56 \%$ female) were students at a mid-sized Midwestern university. They were randomly assigned to pairs and they did not know one another before the study. Of the 26 pairs, 6 were male-male, 9 were femalefemale, and 11 were male-female.

\section{Procedure}

The data for this paper were collected using a variant of the DayTrader task paradigm originally developed by Bos and colleagues [2] and modified by Nguyen \& Canny [12]. DayTrader is a multi-round social dilemma game that requires participants to communicate with each other and establish trust over time in order to perform well (for a critique see [14]). It is the communication sessions used in the service of trust building that we analyze in this paper.

Participants played 28 rounds of the investment game and could chat via IM with their partners for up to 5 minutes after every 5 rounds. Participants were given 60 tokens each round and could either keep or invest any amount in the group market. Withheld tokens guaranteed individuals a two-fold return, while the tokens in the group market were tripled and then split between both participants. Thus, the pair as a whole could make the most by investing all of their tokens in the group market. Withholding contributions from the group increased one's individual earnings but decreased the earnings of one's partner. For this reason, investment in the potentially higher paying group option required a willingness to trust one's partner.

In addition to this general payoff mechanism, we instituted a random market fluctuation of ${ }^{+/} 3$ tokens which allowed players to hide a defection within the market noise. This ability to better hide one's defection creates a more realistic setting because individuals often do not know whether or not they have been cheated [14]. We also awarded a 200 token bonus after every 5 rounds of investment to the partner that earned the most over the previous 5 rounds (partners split the bonus if they earned the same amount). Participants were not informed of bonus earnings until the end of the game, which also made defection harder to detect. Participants were paid between $\$ 10$ and $\$ 25$ based on individual earnings.

\section{Analysis}

Our corpus contained a total of 11,501 words, with an average of 442 words per pair (ranging from 66 to 814). Overall, there were 1,550 lines of chat, with an average of 11.9 lines of chat per chat session.

\section{Linguistic Mimicry Coding Scheme}

We created a coding scheme to measure several types of mimicry between participants, both within and across chat sessions. Our scheme differentiates between simple repetition (e.g., where one person repeats themselves) and mimicry (e.g., where the non-issuing partner repeats something stated by the other person). An instance of mimicry was only counted when both partners used the same term or terms. For example, if $A$ used an expression and $B$ then used the same expression, $B$ 's utterance and all subsequent repetitions by either partner were coded as mimicry. Our scheme consisted of the following categories:

Lexical: repetition of a word or word phrase by both partners, excluding numbers, connecting words (e.g., the, and, or) and being verbs, unless used in conjunction with other repeated words (within and across chat sessions).

A: Have you been investing large or small amounts?

B: small

B: and you?

A: mostly small also

Syntactic: direct repetition of a verb phrase or phrase

structure by both partners within a chat session.

A: if you played fair i would put in 60

B: rounds 19 and 20 you didn't put in $\mathbf{6 0}$ either

Emotion-related Characters: repetition of emoticons or exclamation points by both partners within a chat session.

A: do you want to continue with that plan then?

B: of course!

A: sure thing!

Text-chat Abbreviation: repetition of IM-specific characters (e.g. "u" instead of "you") by both partners within a chat session.

B: what did $\mathbf{u}$ get?

A: how about $\mathrm{i}$ tell you my second to last so $\mathbf{u}$ know i'm telling the truth... 
abbreviations within chat sessions more so than did lowtrusting pairs. Interestingly, low-trusting pairs exhibited more lexical mimicry across chat sessions than did high-trusting pairs. After examining the qualitative chat data, we discovered that lexical mimicry within chat sessions consisted of more content words (e.g. "agree", "invest") whereas lexical mimicry across chat sessions consisted mostly of standard response words (e.g. "yeah", “okay"). These findings suggest that partners who exhibit withinsession mimicry are more attuned to each other's language.

Conversely, partners who exhibit across-session mimicry are merely repeating common forms of social responses. That this type of lower-level mimicry is associated with higher amounts of defection makes sense in light of previous research which suggests that language of deceptive individuals contains fewer markers of cognitive complexity (e.g. motion verbs) $[6,11]$. The argument is that deception requires a certain amount of cognitive effort. If cognitive resources are depleted, deceptive individuals may have fewer resources to attune to a partner's language and thus employ less effortful forms of mimicry rather than more effortful, content-related mimicry. While further work is needed to sharpen the distinction between various forms of mimicry, our findings highlight the importance of considering temporal and structural aspects of mimicry.

\section{FUTURE WORK}

There are a number of ways in which we plan to extend this work. First, although we have identified certain types of linguistic mimicry that are correlated with trust, we lack an understanding of whether mimicry increased trust or trust increased mimicry. By varying the existence of mimicry through an experimental manipulation, we can uncover the causal relationship. In addition, we plan to examine the relationships between trust, mimicry and other variables such as personality traits or propensity to trust others. Research has demonstrated that certain dispositional traits may affect trust outcomes in virtual groups [7] and we aim to incorporate these traits into our model of interpersonal trust in $\mathrm{CMC}$ environments.

\section{ACKNOWLEDGEMENTS}

This research was funded by National Science Foundation grant \#0705901. We thank David Nguyen and Nathan Bos for software and comments on modifications. We also thank John Borland, Nathan Cantelmo, Kathleen Geraghty, Jason Sandler, and our reviewers for their valuable insights.

\section{REFERENCES}

[1] Bavelas, J.B., Black, A., Lemery, C.R., \& Mullett, J. (1986). "I show how you feel": Motor mimicry as a communicative act. Journal of Personality \& Social Psychology, 50, 322-329.

[2] Bos, N., Olson, J.S., Gergle, D., Olson, G.M., \& Wright, Z. (2002). Effects of four computer-mediated communications channels on trust development. In Proceedings of CHI 2002, 135-140.
[3] Chartrand, T.L., \& Bargh, J.A. (1999). The chameleon effect: The perception behavior link and social interaction. Journal of Personality \& Social Psychology, 76, 893-910.

[4] Dimberg, U. (1982). Facial reactions to facial expressions. Psychophysiology, 19, 643-647.

[5] Giles, H., Coupland, J., \& Coupland, N. (1991). Accommodation theory: Communication, context, and consequence. In H. Giles, J. Coupland \& N. Coupland (Eds.), Contexts of Accommodation. Developments in Applied Sociolinguistics. Cambridge University Press.

[6] Hancock, J.T., Curry, L.E., \& Goorha, S. (2008). On lying and being lied to: A linguistic analysis of deception in computer-mediated communication. Discourse Processes, $45,1-23$.

[7] Jarvenpaa, S., Knoll, K., \& Leidner, D. (1998). Is anybody out there? Antecedents of trust in global virtual teams. Journal of Management Info. Systems, 14(4), 2964.

[8] LaFrance, M., \& Broadbent, M. (1976). Group rapport: Posture sharing as a nonverbal indicator. Group and Organization Studies, 1, 328-333.

[9] Maddux, W.W., Mullen, E., \& Galinsky, A.D. (2008). Chameleons bake bigger pies and take bigger pieces: Strategic behavioral mimicry facilitates negotiation outcomes. Journal of Exp. Social Psychology, 44, 461468.

[10] Nass, C.I., \& Lee, K.M. (2001). Does computer-generated speech manifest personality? An experimental test of similarity-attraction. In Proceedings of CHI 2001, 329336.

[11] Newman, M., Pennebaker, J.W., Berry, D., \& Richards, J. (2003). Lying words: Predicting deception from linguistic styles. Personality and Social Psychology Bulletin, 29, 665-675.

[12] Nguyen, D.T., \& Canny, J. (2007). Multiview: Improving trust in group video conferencing through spatial faithfulness. In Proceedings of CHI 2007, 1465-1474.

[13] Niederhoffer, K., \& Pennebaker, J.W. (2002). Linguistic style matching in social interaction. Journal of Language \& Social Psychology, 21(4), 337-360.

[14] Riegelsberger, J., Sasse, A.M., \& McCarthy, J.D. (2003). The researcher's dilemma: Evaluating trust in computermediated communication. International Journal of Human-Computer Studies, 58(6), 759-781.

[15] Rogers, W.H. (1993). Regression standard errors in clustered samples. Stata Technical Bulletin, 13, 19-23.

[16] Tickle-Degnen, L., \& Rosenthal, R. (1990). The nature of rapport and its nonverbal correlates. Psychological Inquiry, 1, 285-293.

[17] Willemyns, M., Gallois, C., \& Callan, V.J. (2003). Trust me, I'm your boss: Trust and power in supervisorsupervisee communication. International Journal of Human Resource Management, 14(1), 117-127.

[18] Wilson, J.M., Straus, S., \& McEvily, B. (2006). All in due time: The development of trust in computer-mediated and face-to-face teams. Organization Behavior and Human Decision Processes, 99(1), 16-33. 